\title{
SUFRÁGIO, EDUCAÇÃo E TRABALHO: \\ O FEMINISMO NA IMPRENSA EM TERESINA NAS DÉCADAS DE 1920 E 1930
}

\author{
SUFFRAGE, EDUCATION AND WORK: FEMINISM IN THE PRESS IN TERESINA IN DECADES \\ OF 1920 AND 1930
}

\author{
Elizangela Barbosa Cardoso* \\ elibcardoso@yahoo.com.br
}

RESUMO: O objetivo deste artigo é analisar a escrita acerca do feminismo, veiculada na imprensa em Teresina (PI), entre os anos 1920 e o início da década de 1930. Procurase enfatizar sua relação com o movimento feminista organizado no Brasil, bem como seu impacto na construção de hierarquias de gênero, na cidade. Argumenta-se que o feminismo se manifesta em Teresina nessas décadas, especialmente, enquanto objeto de debate na imprensa, cujos desdobramentos contribuíram para legitimar o sufrágio, a educação e o trabalho femininos.

PALAVRAS-CHAVE. Feminismo; Imprensa; Gênero.

ABSTRACT: The purpose of this article is to analyze the writing about feminism, conveyed in the press in Teresina (PI), between the 1920's and early 1930. Seeks to emphasize its relationship with the feminist movement organized in Brazil, as well as its impact on construction of gender hierarchies in the city. It is argued that feminism manifested in Teresina in those decades, especially while discussion object in the press, whose developments have helped to legitimize the suffrage, education and women's work.

KEYWORDS: Feminism; Press; Gender.

\footnotetext{
* Doutora em História pela Universidade Federal Fluminense (2010). Professora do Departamento de Geografia e História e do Programa de Pós-Graduação em História do Brasil da Universidade Federal do Piauí
} 
Com a criação da Liga para a Emancipação Intelectual da Mulher, em 1919, por Bertha Lutz e suas companheiras, no Rio de Janeiro, para além de manifestações feministas difusas, presentes desde meados do século XIX, o feminismo se tornou um movimento organizado e de projeção nacional. (HAHNER, 1981).

Segundo Soihet (2006), a Liga objetivava alcançar o reconhecimento dos direitos das mulheres e sua participação na vida pública. Suas demandas por direitos concentravam-se em torno de três palavraschave: educação, emprego e sufrágio. (BESSE, 1999).

Em 1922, em substituição à Liga, foi instituída, no Rio de Janeiro, a Federação Brasileira pelo Progresso Feminino (FBPF), organização que visava reunir mulheres de todo o Brasil que estivessem atuando em prol dos direitos das mulheres ou envolvidas em ação social ou de caridade. Eram objetivos da organização: a promoção da educação da mulher e a elevação de seu nível de instrução, a conquista dos direitos políticos e civis, a proteção de mães e filhos, a consecução de garantias legais que favorecessem o trabalho feminino, a promoção de organizações sociais femininas e a abertura de oportunidades para que as mulheres se engajassem em ações sociais e políticas. (BESSE, 1999).

No período compreendido entre a década de 1920 e o início dos anos 1930, a FBPF cresceu e passou a agregar diversas organizações femininas - sufragistas, profissionais, cívicas e de caridade -, de todos os estados brasileiros (BESSE, 1999).

Durante a década de 1920, sob a liderança de Bertha Lutz, a FBPF e suas associadas lutaram a favor do voto feminino. Na imprensa, respondiam a argumentos antifeministas e, através de manifestos, reuniões públicas, petições e manifestos conseguiram publicizar suas demandas. $\mathrm{Na}$ luta pelo voto, além do "sábio uso de relações pessoais dentro dos círculos 
do governo", apoiaram os políticos favoráveis ao pleito e também atacaram aqueles que eram contrários. (HAHNER, 1981).

Em Teresina, capital do Estado do Piauí, desde o final do século XIX, intelectuais tomavam conhecimento de ação feminista das mulheres na Europa, nos Estados Unidos e em algumas cidades brasileiras, tornando-se sensíveis ao tema. A internacionalização dos movimentos feministas, de que trata Anne-Marie Kappeli (1994, v.4), expressava-se via escrita masculina na imprensa. Assim, diante dos feminismos em vários países do mundo e das incertezas que a demanda das mulheres por direitos políticos e sociais impulsionava, emerge, na imprensa local, um conjunto de textos escritos por homens e algumas mulheres, que debatem o movimento e põem em cena as palavras de ordem do feminismo organizado no Brasil nos anos 1920: educação, trabalho e sufrágio.

A escrita das mulheres acerca do feminismo, em Teresina, é tributária de um conjunto de transformações que atravessam a vida de parte das mulheres das classes alta e média, nas primeiras décadas do século XX. Nesse período, mulheres desses segmentos saíam do espaço privado e de seus papeis, formando uma esfera pública feminina. $O$ acesso à leitura, à escrita, ao lazer, à educação e ao trabalho incorporava-se ao universo de expectativas e também ao campo das experiências femininas.

A Escola Normal Oficial, - instituída em 1910 com a finalidade de profissionalizar a mulher para atuar no magistério primário -, vinha possibilitando o aumento da cultura intelectual feminina e a formação de um universo de leitoras. A leitura, predominantemente masculina, no início do século $X X$, foi então se tornando experiência comum a um conjunto de mulheres. (MAGALHÃES, 1998).

Com o impacto da formação oferecida pela Escola Normal Oficial, processo semelhante ocorreu em relação à produção literária e à escrita na imprensa. (CASTELO BRANCO, 1996; ROCHA, 2007). A participação 
feminina, nesses espaços, que começara a despontar, respectivamente, no final do século XIX e no início do século XX, tornou-se mais nítida nos anos 1920. (ROCHA, 2007). Assim, a Instituição corroborava no delineamento de uma esfera pública feminina, ao colocar a palavra das normalistas em circulação, que, conforme acentua Michelle Perrot (1998), mais do que o espaço material, modela a esfera pública.

A experiência de estudo e de trabalho, o desenvolvimento de projetos pessoais para além do casamento e da maternidade vividos pelas normalistas, bem como o acesso a notícias acerca da dinâmica dos feminismos no mundo ocidental, as tornou sensíveis às demandas feministas. Isto se revela em discursos proferidos quando de solenidades de formatura na Escola Normal, bem como através da escrita na imprensa. Em 1925, a professora normalista Jandira Campelo, no discurso de colação de grau da Escola Normal, assim se expressava:

este é o nosso caso. Seria, para apavorar a cena lembrada e inédita se daqui não saíssemos aparelhadas para lutar e vencer. Outro intuito aliás não tem esta escola. O casamento é uma hipótese.

Daí a necessidade de armar a mulher para triunfar pela inteligência, se as suas graças, as suas virtudes, formosura com que Deus a dotou e distinguiu não conseguirem domar o coração masculino. Felizmente passou o tempo em que se punha em dúvida o intelecto feminino. ${ }^{1}$

Contudo, se pequena parcela das mulheres, especialmente normalistas, identificou-se como o feminismo, não se tem notícias de movimento feminista organizado em Teresina, no contexto em estudo. A esse respeito importa destacar que embora Susan Besse (1999) afirme que a FBPF agregava associadas de todos os estados brasileiros, na documentação pesquisada, não encontrei informações relativas a representantes no Piauí. Olívia Candeia Lima Rocha (2007) acentua que, em 1922 a cronista que escrevia sob o pseudônimo de Dolores, propunha que fosse instituída 
uma representação da FBPF, em Teresina. Projeto que não se concretizara. (ROCHA, 2007).

Desdobramento mais amplo do feminismo, na cidade, fora a configuração de um debate na imprensa em torno do movimento, cujos discursos veiculados denotam representações de feminilidade e de masculinidade que atuaram na construção das relações de gênero. Através dos discursos expressos na imprensa, percebe-se que algumas mulheres e homens se identificavam com o feminismo, ainda que não houvesse consenso quanto à defesa do conjunto de suas demandas.

A identificação feminina com o trabalho extradoméstico e o universo público, fortemente elaborada pelo feminismo organizado, nas décadas de 1920 e 1930, expressava-se via imprensa. A esse respeito, eis o que se lê em Cartas femininas, em julho de 1920, no jornal O Nordeste:

A moça brasileira é geralmente inteligente, carece apenas de instrução; não desta instrução superficial e fictícia com que a maioria das nossas jovens patrícias enfeitam o intelecto, do mesmo modo como que pintam o rosto, para exibir-se; mas de uma boa, sólida e racional instrução, que ao mesmo tempo que lhe ornamente o espírito, habilite-a para enfrentar e vencer a luta sem tréguas da vida moderna. Trabalhemos para isso, se não quisermos continuar a ser a eterna tutelada do homem, e em quem até hoje ele só conhece um préstimo, o de lhe fazer a cozinha, e o de the pregar os botões da ceroula. ${ }^{2}$

No mesmo ano, Sinhá, na referida seção, argumentava:

[...] o feminismo impôs-se e adquiriu nestes quatro anos de guerra mais direitos do que em dezenove séculos passados. As mulheres provaram, que ao lado da abnegação, altruísmo, bondade de coração, elas também possuíam alta capacidade mental, inteligência, caráter tenaz e perseverança, vigor físico bastante para arrastar com os mais duros trabalhos, compreensão dos direitos cívicos e sociais; e que por todas essas qualidades, elas podiam colaborar ao lado do homem como sua companheira e sócia em todos os ramos da atividade humana; nas ciências, nas indústrias e nas artes. E os homens, afinal compreenderam também que tinham que contar com mais esse elemento de luta, e que as mulheres d'ora em diante, não se satisfariam só com os deveres 
por eles impostos, e que precisavam também de direitos. E tiveram que ceder. ${ }^{3}$

Avaliação semelhante à da cronista que escrevia sob o pseudônimo de Sinhá foi recorrente durante a Primeira Guerra Mundial. A referência à ruptura ensejada pelo conflito é ponto comum na literatura e no discurso político, conforme argumenta Françoise Thébaud (1995, v. 5). Contrapondo-se a essa ideia, a autora argumenta que a Grande Guerra foi um momento de vitória da divisão sexual, que seu impacto nas relações entre os homens e as mulheres foi conservador, uma vez que "triunfa o pensamento dicotômico em matéria sexual" em detrimento das demandas igualitárias. Em termos simbólicos, mais que comprovar as capacidades femininas, a Guerra reforçou os mitos da mulher salvadora e consoladora, acrescenta a autora. (THÉBAUD, 1995, v.5, p.13).

Paradoxalmente, segundo Thébaud (1995, v. 5), a Guerra também foi, para as mulheres, uma experiência de liberdade, uma vez que o trabalho feminino a serviço da pátria foi valorizado e as mulheres ingressaram em novas profissões. Por exigência, a Guerra rompeu com a oposição trabalho feminino versus trabalho masculino, que impedia o ingresso das mulheres em diversas profissões.

Logo após a Guerra, em Teresina, a percepção de que as mulheres poderiam ocupar os mesmos espaços que os homens e lutar pelo gozo de direitos iguais, além de fomentar o debate em torno do feminismo na imprensa, impulsionou a professora normalista Josefa Ferraz a candidatar-se ao cargo de Conselheiro Municipal, em 1920. ${ }^{4}$ Em matéria publicada no jornal O Nordeste, comentando o fato, o literato Jônatas Batista ${ }^{5}$ constatava que Teresina não era "de todo indiferente ao simpático movimento feminista que se avoluma no sul do país e que, pouco a pouco, vai se estendendo por todo o Brasil". Para Jônatas, o fato demonstrava adesão feminina ao movimento, 
como também a aceitação das demandas do feminismo pela sociedade. Em suas palavras:

Quer dizer, nada mais nada menos, que o povo, numa proporção animadora, reconhece o direito que a mulher, tanto quanto o homem tem de votar e ser votada, para qualquer cargo eletivo. Com franqueza que o fato nos encheu de entusiasmo e é ainda possuídos desse entusiasmo que mandamos à professora Josefa Ferraz os nossos calorosos parabéns por ter sido, no Piauí, segundo nos consta, a primeira mulher cujo nome aparece nas urnas. É sempre assim que as ideias crescem, ganham solidariedade da opinião pública, tornando-se mais tarde a mais bela e radiante realidade. ${ }^{6}$

Jônatas Batista era defensor dos direitos das mulheres. Assumia postura feminista e não opunha feminilidade e política. Perspectiva oposta, contudo, defendia seu contemporâneo, o poeta Antonio Chaves. ${ }^{7}$ Eis sua avaliação do fato:

[...] com franqueza, não vejo no gesto desses eleitores nenhum movimento feminista. E ainda bem, porque o feminismo começando por essas alturas, teria forçosamente perdido a sua marcha ascendente e chegado ao extremo, ou melhor, chegado ao termo da sua perdição irremissivel, que será a emancipação política da mulher. Ademais, as suas atuais condições de educação e de instrução não the permitem ainda esse direito, e qualquer experiência neste sentido 'seria sofrivelmente aventurosa e muito perigosa para a liberdade e o progresso'. ${ }^{8}$

Antônio Chaves em dois artigos escritos em resposta a Jônatas Batista opunha-se à concessão de direito ao voto através de um conjunto de argumentos. ${ }^{9}$ Acentuava que o baixo nível de instrução das mulheres impedia que alçassem o sufrágio. Isto porque a instrução era fundamental ao exercício da cidadania. Assim, talvez, somente no futuro, as mulheres tivessem condições de reclamar o direito de voto, caso, através da instrução, alcançassem nível intelectual semelhante ao masculino.

Considerava que a política de conchavos, dominante no período, impunha um cativeiro político ao cidadão, impedindo que a maioria dos 
homens pudesse usufruir autonomia e liberdade política. E caso as mulheres se tornassem eleitoras, mais presas seriam, ainda, aos ditames da política reinante, uma vez que eram dominadas pelas paixões. Isso seria, então, uma aventura perigosa que ameaçava a liberdade e o progresso.

Para Chaves, mulheres que demandavam direitos políticos seriam anarquistas - ideologia política que, em sua perspectiva, desagregava o social e ameaçava o Estado. Além de anarquistas, as mulheres políticas, para o poeta, eram revolucionárias - fato altamente perturbador. Em sua leitura, caso lhes fosse concedido o direito de voto, em menor número, elas não lograriam vitórias e, consequentemente, contestariam as leis e o governo em praça pública e incitariam à revolução. Em seus termos:

Mulher política é sinônimo de mulher anarquista. E não desejo vê-la fomentando o movimento socialista, lançando panfletos incendiários como bombas, inflamadas sobre a noite trevosa do tumulto operário.

Não quero vê-la derramando e espalhando as suas cóleras como Júpiter os seus raios, procurando, assim, infundir na alma do povo uma forte emoção de terror e de respeito.

Não quero vê-la, ainda, possuída de poder mágico da hipnose com fascinação misteriosa de seu olhar, proclamando temíveis e arrojadas utopias sociais e tentando, por esta forma com a sua palavra magnética, ter domínio sobre a multidão e hipnotizar os ouvintes.

O ser frágil e delicado da mulher não deve ocultar o veio de energia e de força que o possa fazer arrogante, poderoso e temido. Seria a sua masculinização. E a mulher nesse estado, ela que é a fonte da beleza eterna e o símbolo do amor perderia todo o seu encanto e seria a exterminadora voluntária do grande império, do domínio absoluto que exerce sobre o nosso sexo. ${ }^{10}$

$[\ldots]$

Não quero ver o anjo do lar transformado em revolucionária das ruas. E essas outras mulheres de que fala Jônatas Batista, 'que pensam de modo diferente e que preferem a liberdade na terra a esse papel ingênuo de 'serafins de capela', indiferente ao progresso, 'ao movimento político', são justamente as candidatas ao anarquismo, de 
que falei no meu primeiro artigo, porque são justamente as mulheres políticas.

$[\ldots]$

O que não fariam as mulheres de posse da sua liberdade política? Formando um número limitadíssimo em relação ao do homem e, portanto, incapazes, sem forças para vencerem uma campanha política qualquer, elas iriam para a praça pública acusar as leis, expropriar os atos do governo, pregar a revolução, porque, quer quiser que se iluda, elas não querem adquirir o direito de voto apenas para trabalharem conosco na obra da civilização. ${ }^{11}$

Antônio Chaves considerava que a mulher na política teria poder de hipnotizar, embriagar e conclamar o povo à revolução. Atribuindo esses poderes à mulher, caso alcançasse o direito de voto, o poeta permite perceber que, no imaginário do período, a mulher que buscava igualdade política era vista como uma mulher poderosa, que amedrontava e causava horror. Para Chaves, a luta por direitos políticos constituía um feminismo que estaria levando ao extremo a demanda de igualdade. Esta perspectiva revela a ansiedade despertada pelo questionamento dos lugares de gênero na política, desencadeada pelo feminismo.

Segundo Chaves, o ingresso da mulher na política implicaria sua masculinização. Nesse estágio, a mulher perderia todo o seu encanto e beleza, bem como o prestígio de que gozava junto ao homem, tornando-se objeto das paixões e ressentimentos, que atravessam a política. ${ }^{12} \mathrm{~A}$ mulher, então, deixaria de ser percebida como mulher, para se tornar um homem na contenda pela vida. Nas palavras do autor:

[...] A mulher fora do lar, pleiteando uma eleição como eu, como eu coberta da poeira ou da lama de nossas lutas acerbas, é um homem como eu, um meu rival, que posso odiar ou espezinhar sem remorsos, porque, na luta da vida, é a lei fatal o mais forte matar ou prostrar o mais fraco. ${ }^{13}$

No discurso de Antônio Chaves, opunha-se à mulher política, a mulher amorosa (mãe, esposa e filha). Se a primeira - que era um espectro 
que assombrava parte dos homens - poderia exercer poder através da emoção, do terror e do respeito, que era capaz de despertar, através de sua palavra magnética e do poder de hipnotizar multidões; a segunda, o exerceria por meios indiretos e difusos. Era através do amor, da beleza, da arte de influenciar, de agradar, bem como mediante a educação e a socialização de novas gerações que dominaria. Símbolo de amor, era mediante esse sentimento que essa mulher poderia auferir prestígio, reconhecimento e poder. Através do amor conjugal, filial e maternal exerceria domínio.

Compartilhando os temores de Antônio Chaves, outros argumentavam que as mulheres na política deixariam de desempenhar os papeis para os quais teriam nascido - os de mãe, esposa e dona-de-casa. Assim, defendiam que o voto não fosse concedido à mulher, para que ela se mantivesse no lugar que lhe era devido - o lar.

Atribuindo-se a razão ao homem e a sensibilidade à mulher, argumentava-se também que em decorrência de suas faculdades sensíveis, a mulher não lograria desempenhar a contento as obrigações políticas. ${ }^{14}$

Outros ainda consideravam que o ingresso feminino na esfera política implicaria em conflitos domésticos e conjugais. É o que se depreende, a partir do seguinte trecho:

O voto feminino... Imaginem os Srs. a complicação nos lares, quando o marido, vexado para almoçar, porque já deve estar sendo feita a chamada da eleição a que tem de ir, pedir providências à mulher, e esta Ihe bradar aos queixos que também está vexada, porque igualmente vai votar... E quando as opiniões divergirem - votando a mulher em candidato contrário ao do marido ${ }^{15}$

Em 1924, Cristino Castelo Branco em discurso proferido na Escola Normal Oficial, quando da formatura das normalistas, acentuava:

A mulher política, a mulher eleitora, a mulher deputada, como a querem fazer atualmente, é a mulher fora da sua finalidade. A mulher nasceu para ser mãe e para ser professora. Porque, se 'ser mãe é desdobrar fibra por fibra o coração', - ser professora é fazer do coração a fonte da sabedoria. ${ }^{16}$ 
As referidas avaliações em torno do sufrágio feminino revelam que a problematização das demandas feministas punha em cena definições de feminilidade e de masculinidade que atuavam na construção das relações de gênero no período em estudo. Recorrentemente, associava-se mulher e maternidade, bem como masculinidade e política. Tratava-se de associações que desde a Revolução Francesa contribuíam para excluir as mulheres dos direitos de cidadania. (BADINTER, 1991; SCOTT, 2002). Assim, a inscrição da cidadania enquanto apanágio masculino, delineada nos referidos discursos, corroborava para exclusão das mulheres nessa esfera.

A despeito disso, no mesmo período, mulheres formadas na instituição na qual Cristino Castelo Branco defendia a negação dos direitos políticos, em 1924, vinham opondo-se à sua perspectiva através da escrita na imprensa e também mediante tentativa de redefinir o campo político, com a inclusão feminina, como o fez a professora normalista Josefa Ferraz.

$\mathrm{Na}$ tentativa de instituir o direito ao voto, mulheres que se identificavam com o feminismo argumentavam que a presença feminina na política era fundamental à democracia e ao seu levantamento moral, que sua presença nessa esfera não inviabilizava o exercício da maternidade. Contrapondo-se a esse argumento, Cristino Castelo Branco acentuava:

Não é atribuindo à mulher o direito de sufrágio que melhoraremos as condições políticas de nossa pátria. O que levantará a nossa pobre democracia é a alfabetização das massas, é o voto secreto, é a educação moral e cívica da mocidade. ${ }^{17}$

Nos anos 1920, dentre as demandas feministas, a que sofria mais ampla oposição era a aquela por direitos políticos. Antônio Chaves e Cristino Castelo Branco não eram vozes isoladas. Na verdade, veiculavam modo de perceber a questão compartilhada por parte da sociedade, inclusive, pelas mulheres. Em 1925, a cronista Acácia, assim se manifestava no jornal O Piauí:

No lar é que se formam os homens e que será deste lar abandonado pela mulher que anda nas conferências políticas, nos meetings para 
eleger seu candidato, e só a ele regressa, quando procura o repouso das lides públicas ${ }^{18}$

A cronista Eglantine, por sua vez, em resposta a uma leitora que qualificava de feminista apaixonada e exaltada, acentuava: "As mulheres com direitos de voto? Para quê? Qual a vantagem que daí lhes resultaria? No meu entender nenhuma. Não, minha amiguinha, não pode ser este o verdadeiro feminismo $[\ldots]^{\prime \prime}$.

Em torno do feminismo enquanto movimento social e político, homens e mulheres defendiam tanto ideias antifeministas quanto feministas. Seguindo perspectiva feminista, Costa Rego defendia o acesso das mulheres aos mecanismos representativos, no campo da política institucional. 0 cronista expressava posição favorável ao voto feminino em artigo publicado no jornal $O$ Nordeste, em 6 de novembro de 1920. Nesse artigo, argumentava que o sufrágio não havia sido concedido às mulheres por puro preconceito, lembrando, ainda, que, de certa forma, os direitos políticos eram assegurados às mulheres, pela Constituição. Isto porque "se não é explícita, é implícita", quanto ao sufrágio feminino. ${ }^{19}$

Em um momento de amplo descontentamento com a política vigente (QUEIROZ, 1996), Costa Rego era aberto à possibilidade de governo feminino. Ele considerava que as mulheres deveriam votar e serem votadas, "ao menos para adquirir a experiência do que farão [...] num país que tem sido tão mal governado pelos homens". ${ }^{20}$

Em conferência proferida no Cenáculo Piauiense de Letras, em 7 de junho de 1928, Torres Raposo, abordando o feminismo, mostrava-se favorável à concessão de voto às mulheres. Em sua avaliação, a emancipação feminina era uma realidade, pois no âmbito da Primeira Guerra Mundial, a mulher se libertara de grilhões que há tempos remotos a prendiam, e vários países haviam promulgado o sufrágio feminino. Assim, não via nenhuma inconveniência em conceder direitos de voto às mulheres. Lembrava àqueles 
que receavam a reforma dos costumes políticos e das instituições em vigor, que seus medos não tinham fundamento, uma vez que bastava olhar o que vinha ocorrendo, na prática, em vários países da Europa, após o sufrágio feminino. Ademais, destacava que o argumento de que o Brasil era um país jovem e o voto feminino poderia perturbar a formação da personalidade do país também não se sustentava. 0 direito ao voto, em sua leitura, "era mais uma oportunidade que se oferecia às mulheres brasileiras para libertarem-se da tirania de preconceito caducos." Em seguida, acrescentava: "Talvez elas realizassem o que até hoje, apesar dos discursos e plataformas brilhantes, não lograram realizar muitos homens públicos no Brasil.... ${ }^{21}$

Além de demanda por sufrágio, o feminismo também era percebido como movimento que possibilitaria instrumentalizar as mulheres para melhor desempenharem funções no âmbito da família. Esta era uma posição de Higino Cunha ${ }^{22}$ expressa no texto $A$ educação feminina e o regime conjugal23, de 1924, no qual defendia a educação e a valorização da mulher a partir dos papeis tradicionais, especialmente o de mãe.

Nessa perspectiva, é visível a ênfase na maternidade na reivindicação de direitos. A grande dimensão que a maternidade ocupou nas teorias desenvolvidas pelos primeiros movimentos de mulheres, no mundo Ocidental, em sua luta pela cidadania, também permeava concepções de feminismo em Teresina. (BOCK, 1995, v. 5). A condição de mãe era enfatizada para reivindicar direitos, sobretudo, à educação.

Contrariamente à demanda por direitos políticos, havia maior abertura em relação à educação e ao trabalho femininos. Nos segmentos mais abastados, havia consenso em torno da necessidade de educar as mulheres. A discussão configurava-se em torno do nível e da finalidade dessa educação. Que a mulher estudasse para a função de mãe esclarecida, sem aspiração ao nível de doutora, era uma forma de perceber a educação feminina; que a mulher fosse educada a partir de princípios científicos e racionais, para 
desempenhar a contento as funções de mãe, esposa e dona-de-casa e também aquelas consideradas compatíveis à condição de mulher, era outro ideal de educação feminina; que a mulher fosse educada para o exercício profissional era perspectiva defendida por mulheres que se identificavam com o feminismo.

Em oposição à emancipação política feminina, Antônio Chaves defendia que as mulheres fossem educadas, a partir de princípios modernos, para exercer funções familiares, e que se emancipassem através do trabalho e do estudo. Conforme conceituara, em 1920, o feminismo, no Brasil, não era mais que um movimento pela instrução feminina, para que as mulheres detivessem habilidades que as livrassem dos maus casamentos - o que considerava louvável. Em artigo em que refutava os argumentos de Jônatas Batista a favor do feminismo, Antônio Chaves acentuava:

Eu pertenço ao número daqueles que entendem que a mulher deve procurar o mais possível, pelo trabalho e pelo estudo, melhorar as suas próprias condições intelectuais, materiais e morais. A sua independência social é digna de todo acatamento, convindo, no entanto, acrescentar que essa independência não deve ultrapassar os direitos da sua atividade feminina. E ela própria, a mulher, com o raciocínio da sua inteligência, compreenderá facilmente que é impossível, adquirir e conservar a sua liberdade social, senão pelo trabalho auxiliado pela ciência. ${ }^{24}$

Antônio Chaves era favorável ao estudo e ao trabalho femininos, desde que fossem restritos a áreas de atuação consideradas adequadas às mulheres. Em sua perspectiva, a educação e o trabalho deveriam ser demarcados pelo gênero. Predomina no discurso de Chaves leitura dicotômica que reforça desigualdades de gênero nessas esferas.

Difundindo um novo ideal de dona-de-casa - aquele que tinha por base a escolarização do doméstico - Chaves valorizava as instituições que vinham formando a mulher para o lar, a partir de princípios racionais.

E já hoje, mesmo no Brasil, existem escolas, com frequência animadora, onde a mulher consciente dos seus futuros deveres, vai 
beber os ensinamentos imprescindíveis aos misteres do lar. E oxalá que as minhas patrícias, as mais competentes na matéria, auxiliadas por intelectuais vontadosos, fundassem em nosso meio uma dessas escolas para instruírem as nossas moças, o que certamente lhes seria de grande vantagem. ${ }^{25}$

Em abril de 1926, a cronista Violeta conclamava, por sua vez, as mulheres a se habilitarem a partir de uma sólida instrução, que as pudesse tornar independentes.

Cultive a mulher o seu espírito, aprimore os seus dons naturais, habilite-se por uma sólida e bem cuidada instrução para lutar com eficiência pela vida e ter-se-á tornado não livre, mas independente.

Tendo a sua personalidade própria, sabendo-se dirigir com firmeza e segurança, consciente de seu próprio valor, estará apta a fazer por si o seu futuro, não aguardando apenas, por um único destino ambicionável e possível - o casamento. ${ }^{26}$

Na leitura da cronista, a educação feminina deveria funcionar em prol da autonomia. Em vez de formar as mulheres para melhor exercer os papeis tradicionais, centrados no casamento e na maternidade, a educação propiciaria alternativa ao casamento, na medida em que favorecia condições de independência em relação a este. Com esta perspectiva, a cronista situava-se em uma tradição de crítica às amarras limitadoras da educação feminina, cujo cerne era a valorização da educação e do trabalho produtivo como formas de emancipação e de inserção social. (BESSE, 1999).

Importa destacar que o acesso das mulheres à educação e ao trabalho foi questão de primeira ordem no feminismo organizado, nos anos 1930, no Brasil. Aproveitando abertura política configurada com a Revolução, a FBPF, além do direito ao voto, trabalhou pela instituição de mecanismos jurídicos e institucionais que assegurassem a igualdade de gênero no que diz respeito à educação e ao trabalho. No ano de 1931, a Organização realizou, no Rio de Janeiro, sua segunda convenção internacional. Segundo Susan Besse (1991), a convenção durou onze dias, contando com representantes de 
todos os estados do Brasil, de vinte e oito organizações femininas, de caráter cívico, de assistência social, profissional e sufragista; e dezoito organizações estrangeiras. Na oportunidade, foram formuladas recomendações em prol de mudanças constitucionais e legais, assim como políticas sociais que visavam favorecer os direitos das mulheres.

Na convenção, a FBPF declarou que o problema central do movimento era a emancipação econômica feminina. Com o intuito de alcançá-la, a convenção instituiu e reivindicou um conjunto de medidas, dentre as quais: educação pública orientada para a profissionalização feminina; rigoroso padrão higiênico nos locais de trabalho, implementação de salário mínino, salário igual para o mesmo trabalho, fosse desempenhado por homem ou por mulher; direitos iguais no ingresso ao serviço público, licença-maternidade; racionalização dos programas de assistência pública, o que incluía a promoção da função de assistente social; o reconhecimento da economia doméstica e do valor das atividades econômicas desempenhadas pelas donas-de-casa para a economia nacional. (BESSE, 1991).

Na primeira metade dos anos 1930, o feminismo de Bertha Lutz e de suas companheiras e a dinâmica do feminismo internacional eram noticiados na imprensa, em Teresina. ${ }^{27}$ Assim como ocorrera na década de 1920, era comum a reprodução de matérias publicadas no Rio de Janeiro na imprensa local.

Os artigos que circulavam na imprensa, no início dos anos 1930, mostram que o feminismo e as demandas por educação, trabalho e sufrágio passavam a ter maior aceitação social. Na década de 1920, os posicionamentos antifeministas eram mais recorrentes e exacerbados. Parte daqueles e daquelas que se identificavam como feministas impunham ressalvas ao movimento, enquanto na primeira metade dos anos 1930, na imprensa, predominou perspectiva favorável ao feminismo. 
Em 17 de maio de 1931, Emanuel Machado Lopes, defendia o sufrágio feminino. Em seus termos:

Efetivamente, a mulher já era eleitora antes de o homem ter domínio social. Como detentora do feudo tinha os mesmos direitos que os senhores feudais: levantava exército, fazia justiça, fabricava moeda, prestava e recebia homenagens. Cidadã, ela elegia com os cidadãos os magistrados. Tudo isto, porém, ruiu por terra com o aniquilamento do regime feudal [...].

Foi, entretanto, a grande guerra mundial o avanço formidável do extraordinário triunfo do feminismo. Tão valiosa foi a cooperação da mulher nessa luta sangrenta, que os mais circunspectos estadistas the fizeram a justiça de conceder direitos em proporção ao mérito por ela revelado.

[...] Essa profunda e indiscutível modificação torna, por assim dizer, inaproveitável, nos nossos dias, o juízo dos nossos antepassados e, obriga-nos a realizar, à luz da nova mentalidade, essa grande aspiração da época, qual a do direito de sufrágio feminino, que representa a mais esplêndida conquista que registrar possam aos anais da história político-contemporânea. ${ }^{28}$

Contudo, alguns aceitavam o sufrágio feminino, com ressalvas, conforme se depreende a partir da avaliação de Walter Alencar.

Sufrágio feminino. É verdadeiramente difícil, uma solução que, amenize esta classe em luta, para adquirir um direito conspurcado, porém torna-se impossível, que a referida medida, abranja totalmente - a mulher em geral. Não só porque tornar-se-á uma verdadeira balbúrdia no prélio eleitoral, como inacabáveis serão as nossas eleições. ${ }^{29}$

O ideal de educação formadora unicamente da mãe/esposa/ dona-de-casa perde visibilidade e, ao mesmo tempo, é reafirmada a necessidade de educação para que as mulheres possam dispor de liberdade social e de independência econômica. Em julho de 1932, B. M. Monteiro, posicionava-se acerca da questão, nos seguintes termos:

Eduque-se a mulher em todos os ramos da atividade humana, lendo tudo, conhecendo tudo, sabendo manejar tão bem a pena, o martelo, o automóvel, a locomotiva, o transatlântico, o torpedeiro, o submarino, o avião, o arado, a ceifadeira, o fuzil e o canhão, como uma agulha. 
Despertai, mulheres, e deixai o toque de melindres com que vos capacitam de sexo fraco, quando em verdade sois fortes povoadoras do solo.

Pleiteai com desassombro a conquista de vossos direitos, raciocinai, auscultai a consciência e analisando os fatos sem mistificações, tereis, então, pela certeza de que nada serão os homens sem o vosso concurso, pois, sois irmãs, filhas, esposas e mães.

Sem mulher, nada.

Avante! $!^{30}$

Em discurso proferido quando da formatura das normalistas, em 1935, Edson Cunha, posicionou-se acerca da questão, argumentando: "Não podemos conceber mais o isolamento da mulher no lar. A sua educação impõe-se. A sua atividade está reconhecida e ela deve ser armada de meios necessários à luta." ${ }^{11}$

Carlos Alberto, em 14 de maio de 1933, decepcionado com a atuação das agremiações eleitorais, que, na sua avaliação, não lograram a indicação de bons candidatos, considerava que, para salvar a política no Piauí, seria necessário contar com a ação feminina. Para intervir nessa esfera, as mulheres deveriam criar uma União Feminina com o objetivo de indicar candidatos e combater as injunções da política profissional.

A mulher piauiense poderá realizar uma obra de inestimável valor cívico, criando um grêmio cuja finalidade inabalável seja aquela cujo fracasso estamos assistindo.

Para isso, basta que se ponha superiormente em unidade de vistas, e, como garantia à eficiência do seu esforço, comece declarando guerra franca às tapeações e cambalachos costumeiros.

Aqui deixamos sugerida a criação da União Feminina e confiamos que as nossas valorosas patrícias, isentas de preconceitos fúteis ou timidez doentia, pensem no que ele poderá trazer de benefícios ao Piauí, realizando uma campanha sã, de educação política. Entre todas, decididas, pois, na reivindicação dos seus legítimos direitos e no melhor serviço à nossa terra. ${ }^{32}$ 
Cunha e Silva, em artigo de 1934, denominado A mulher, identificando-se com o feminismo, questionava a inferioridade física e intelectual feminina. Para o jornalista, em termos físicos, para demonstrar o preconceito que inscreve a inferioridade no corpo feminino, bastaria que as mulheres recebessem educação física semelhante à masculina. No que diz respeito à suposta inferioridade intelectual, para questioná-la, que fosse concedido à mulher "liberdade para exercer quaisquer profissões ou dedicarse a quaisquer ciências". Em seguida, acrescentava: "A tal debilidade mental e física da mulher é, pois um mito. É um preconceito do qual se utilizou o homem para satisfação de gozo material e de injusto e ilógico predomínio de sexo"..$^{33}$

Cunha e Silva considerava que a vida feminina naquele período se distanciava das formas experienciadas por gerações de mulheres, no passado. O momento de sua escrita seria de transformações na vida feminina, cujos desdobramentos ainda não poderiam ser avaliados, o futuro diria, contudo. O certo é que o feminismo seguia sua marcha e, certamente, avançaria na conquista de direitos.

Essa forma de perceber as possibilidades do tempo era compartilhada por outros contemporâneos e contemporâneas. Segundo um cronista, nos tempos que corriam

[...] é sabido que a mulher já se acha equiparada ao sexo forte sob múltiplos aspectos. Ela deixou de ser a boa dona-de-casa, presa aos afazeres domésticos e aos cuidados das crianças, para, travestindose de homem, conseguir as liberdades e direitos até então somente usufruídos por este. E dia a dia, de vitória em vitória, ela prossegue, sem estacada, nessa vertigem de conquistas, sem saber aonde vai parar...34

A avaliação dos cronistas, na verdade, articulava-se à dinâmica do feminismo no Brasil, bem como a mudanças configuradas na experiência de um conjunto de mulheres ocidentais, no período. Em relação ao primeiro aspecto, em grande medida por decorrência da ação da FBPF, o direito de 
voto foi concedido às mulheres, através de decreto de 24 de fevereiro de 1932. (SOIHET, 2006).

O trabalho da FBPF passou, então, a ser orientado no sentido de assegurar os direitos previstos na Constituição. ${ }^{35} \mathrm{As}$ convenções realizadas nos anos de 1934 e 1936 reforçaram a necessidade de um programa que visasse consolidar e ampliar as conquistas previstas na lei. A ênfase central das convenções incidiu sobre a necessidade de oportunidades iguais de trabalho. (SOIHET, 2006).

Para Bertha Lutz, a emancipação econômica era fundante em relação às demais formas de emancipação. Nesse sentido, em 1936, a FBPF reivindicou que o governo criasse um Estatuto da Mulher, com o objetivo de assegurar, a despeito do estado civil, a dedicação da mulher a qualquer atividade econômica ou profissional, e que também as protegesse contra discriminação. As convenções também investiram esforços para reformar o Código Civil, no intuito de estabelecer igualdade entre mulheres casadas e seus maridos. Quanto ao Código Penal, visavam alterações que assegurassem que homens e mulheres envolvidos em adultério e prostituição fossem tratados de forma igual. (BESSE, 1991; HAHNER, 1981; SOIHET, 2006).

Em 1936, Bertha Lutz tomou posse como deputada federal. Assumiu a presidência da Comissão Especial do Congresso para o Estatuto da Mulher. Dentre as feministas, havia a expectativa de que as propostas e reivindicações da FBPF fossem consideradas pelo Congresso (SOIHET, 2006).

Em relação ao segundo aspecto, em termos locais, a educação profissional feminina passava a ser vista como uma forma de inserção social, um mecanismo que poderia assegurar às mulheres uma forma de vida digna, caso se tornassem viúvas ou não se casassem. A configuração de um sistema escolar em Teresina, nas primeiras décadas do século $X X$, somado à percepção de que as mulheres também deveriam ser escolarizadas foi transformando a experiência feminina no que tange à educação formal, sobretudo nas 
classes alta e média. Conforme dados divulgados no censo demográfico de 1940, é possível acentuar que, embora as mulheres continuassem menos alfabetizadas do que os homens, nos grupos etários mais jovens, entre $10 \mathrm{e}$ 19 anos, a proporção de mulheres que sabia ler e escrever era mais ampla do que a masculina, isto porque, a rede escolar se expandiu nos anos 1930 e as mulheres mais jovens passaram a ter mais acesso à escola do que tiveram aquelas das gerações anteriores. (CARDOSO, 2012).

A Escola Normal até o início dos anos 1930 era a instituição que propiciava o mais alto nível de escolarização para as mulheres no Estado, dando vazão ao desejo de emancipação que atravessou a década de 1920, uma vez que, na perspectiva de parte das mulheres, a formação como professora primária era vista como meio para alcançar a independência. (CARDOSO, 2012).

Em meados da década de 1930, a presença feminina no sistema escolar também se expandiu no ensino secundário não profissionalizante. Em relação ao ensino superior, até a década de 1930 era reduzidíssimo o número de mulheres com formação nesse nível. Para esse quadro corroborava o fato de a primeira instituição voltada para esta modalidade de ensino datar somente de 1931, quando foi instalada a Faculdade de Direito (FADI), em Teresina. (CARDOSO 2012).

Paralelamente à expansão da escolarização feminina, legitimouse a inserção feminina no mercado de trabalho, predominantemente em áreas que se feminizavam no contexto. Nas décadas de 1920 e 1930, o magistério primário concentrou a maioria das mulheres de classe média ingressas no mercado de trabalho. A ampliação da rede escolar pública criou condições de inserção e permanência feminina no mercado de trabalho. Ademais, no desenvolvimento de políticas públicas, nas áreas de educação e de saúde, bem como na administração pública, o Estado recrutou mão de obra feminina. 
As expectativas e as experiências das mulheres das classes alta e média transformavam-se, especialmente, no que tange ao estudo e ao trabalho. Nesse processo, as polêmicas em torno do feminismo na imprensa atuaram no sentido de tornar o ensino, o trabalho e o sufrágio apanágios femininos.

Notas

(Endnotes)

1 ESCOLA Normal. O Piaui, Teresina, ano XXXVII, n. 17, p. 4, 20 jan. 1925. In: CASTELO BRANCO, 1996, p. 79.

2 CINHÁ. Cartas femininas. O Nordeste, Teresina, ano 1, n. 32, p. 4, 3 jul. 1920.

3 SINHÁ. Cartas femininas. O Nordeste, Teresina, n. 19, 3 abr. 1920.

4 A Constituição do Estado do Piauí, de 12 de janeiro de 1891, estabeleceu que o poder nos municípios deveria ser exercido por um conselho municipal, que tinha competência para deliberar sobre os serviços importantes à vida econômica e administrativa do município, bem como por um intendente, executor das deliberações do conselho. Estabelecia, ainda, que os cargos de conselheiro municipal e de intendente deveriam ser eletivos, com mandatos de quatro anos. $\mathrm{O}$ articulista, portanto, tratava desta modalidade de eleição, especificamente, para o cargo de conselheiro municipal. Ver PEREIRA, José Eduardo; OMMATI, Fides Angélica. As constituições piauienses. Teresina: Projeto Petrônio Portella, 1988. p. 184.

5 Jônatas Batista nasceu em Natal, hoje, Monsenhor Gil, em 1885, falecendo em São Paulo, em 1935. Grande animador cultural nas primeiras décadas do século XX, em Teresina, um dos fundadores da Academia Piauiense de Letras, foi poeta, jornalista e teatrólogo. Ver GONÇALVES, Wilson Carvalho. Dicionário enciclopédico piauiense ilustrado: 15492003. Teresina: Halley, 2003.

6 O FEMINISMO em Teresina. Teresina, O Nordeste, ano 1, n. 51, p.3, 20 nov. 1920

7 Nasceu em 26 de abril de 1882 e morreu em 22 de fevereiro de 1938, em Teresina. Foi poeta, conferencista e jornalista de intensa atividade. Ver GONÇALVES, 2003.

8 CHAVES, Antonio. O feminismo em Teresina. O Piauí, Teresina, ano 21, n. 430, p. 1, 28 nov. 1920.

9 CHAVES, Antonio. O feminismo em Teresina. O Piauí, Teresina, ano 21, n. 430, p. 1, 28 nov. 1920; CHAVES, Antonio. O Feminismo. O Piauí, Teresina, ano 21, n. 433, p. 1, 9 dez. 1920.

10 CHAVES, Antonio. O Feminismo. O Piauí, Teresina, ano 21, n. 430, p. 1, 28 nov. 1920. 
11 CHAVES, Antonio. O Feminismo. O Piauí, Teresina, ano 21, n. 433, p. 1, 9 dez. 1920; CHAVES, Antonio. O Feminismo. O Piauí, Teresina, ano 21, n. 430, p. 1, 28 nov. 1920.

12 CHAVES, Antonio. O Feminismo. O Piauí, Teresina, ano 21, n. 433, p. 1, 9 dez. 1920; CHAVES, Antonio. O Feminismo. O Piauí, Teresina, ano 21, n. 430, p. 1, 28 nov. 1920

13 CHAVES, Antonio. O Feminismo. O Piaui, Teresina, ano 21, n. 433, p. 1, 9 dez. 1920.

14 ACÁCIA. O feminismo. O Piauí, Teresina, ano 27, p. 4, 28 nov. 1925.

15 PASCHOALINO. Comentários e notícias. Gazeta, Teresina, ano 17, n. 762, p. 1, 17 dez. 1927.

16 CASTELO BRANCO, Cristino. Discurso proferido pelo Dr. Cristino Castelo Branco, paraninfando a colação de grau das professoras, na Escola Normal, a 14 do corrente. Revista da Academia Piauiense de Letras, Teresina, ano 11, p. 146-149, n. 12, jan. 1928.

17 CASTElO BRANCO, Cristino. Discurso proferido pelo Dr. Cristino Castelo Branco, paraninfando a colação de grau das professoras, na Escola Normal, a 14 do corrente. Revista da Academia Piauiense de Letras, Teresina, ano 11, n. 12, p. 146-149, jan. 1928.

18 ACÁCIA. Feminismo. O Piauí, Teresina, ano 27, n. 273, p. 4, 28 nov. 1925.

19 REGO, Costa. A mulher na constituição. O Nordeste, Teresina, ano 1, n. 49, p.1, 6 nov. 1920.

20 REGO, Costa. A mulher na constituição. O Nordeste, Teresina, ano 1, n. 49, p.1, 6 nov. 1920.

21 RAPOSO, Torres. O Feminismo. A Revista, Teresina, n. 2, v. 2, 7 dez. 1928.

22 Higino Cícero da Cunha nasceu a 11 de janeiro de 1858, em São José das Cajazeiras, hoje, Timon (MA), falecendo em 16 de novembro de 1943, em Teresina. Bacharel em Direito pela Faculdade de Direito do Recife (1885), professor do Liceu Piauiense, da Escola Normal Oficial e da Faculdade de Direito do Piauí, jurista, magistrado e escritor. Ver GONÇALVES, 2003. p. 143.

23 CUNHA, Higino. A educação feminina e o regime conjugal. Revista da Academia Piauiense de Letras, Teresina, ano VII, p. 37-52, maio 1924.

24 CHAVES, Antonio. O Piauí, Teresina, ano 21, n. 430, 28 nov. 1920.

25 CHAVES, Antonio. O Piauí, Teresina, ano 21, n. 430, 28 nov. 1920.

26 VIOLETA. Feminismo. O Piauí, Teresina, ano 27, n. 75, 6 abr. 1926.

27 O ELEMENTO feminino na elaboração da Carta Constitucional. A Liberdade, Teresina, ano 5, n. 157, p. 2, 17 dez. 1932; RETALHOS: a vitória das saias. A Imprensa, Teresina, ano 2, n. 7, p. 2, 27 abr. 1933; CROTMAN, Rachel. Restrições criadas ao trabalho feminino. A Liberdade, Teresina, ano 7, n. 193, p. 4, 23 jun. 1934; CROTMAN, Rachel. O momento feminista brasileiro. A Liberdade, Teresina, ano 7, p.3, 14 jul. 1934; CONTRA o voto das mulheres. A Liberdade, Teresina, ano 7, n. 189, p. 2, 23 maio 1934; CROTMAN, Rachel. A 
mulher moderna. A Liberdade, Teresina, ano 7, n. 206, p. 2, 13 out. 1934; PADILHA, Leão. O desvirtuamento do voto feminino. O Tempo, Teresina, ano 2, n. 344, p. 1, 14 dez. 1934; O FRACASSO moral do feminismo. O Tempo, Teresina, ano 3, n.388, p. 1, 7 fev. 1935; A RUIDOSA política das mulheres. O Tempo, Teresina, ano 3, p. 3, 16 fev. 1935.

28 LOPES, Emanuel Machado. Sufrágio feminino. Nego, Teresina, ano 1, n. 1, p. 5, 17 maio 1931.

29 ALENCAR, Walter. A constituinte e o voto secreto - sufrágio feminino. Nego, Teresina, ano 1, n. 2, p. 2, 24 maio 1931.

30 MONTEIRO, B. M. A mulher e a conquista de seus direitos. A Liberdade, Teresina, ano 5, n. 149 , p. 4, 10 jul. 1932.

31 CUNHA, Edson. Pela instrução pública. Diário Oficial, Teresina, ano 6, n. 4, p. 1 e 4, 7 jan. 1936.

32 ALBERTO, Carlos. A União Feminina. O Piauí, Teresina, ano 1, n. 13, p. 1, 14 maio 1933.

33 SILVA, Francisco Cunha e. A mulher. O Tempo, Teresina, ano 2, n. 339, p. 2, 8 dez. 1934.

34 DREYFUS. O feminismo avança. O Piauí, Teresina, ano 1, n. 21, p. 4, 11 jun. 1933.

35 Sob pressão da FBPF, além do sufrágio, algumas mudanças significativas foram introduzidas na Constituição de 1934, dentre as quais, destacam-se: a possibilidade das mulheres brasileiras manterem a nacionalidade e a transmitirem aos filhos, quando casadas com estrangeiros; igualdade de mulheres e homens perante a lei; na legislação trabalhista: o mesmo pagamento para trabalho igual, oito horas de trabalho diárias, férias anuais remuneradas, saláriomaternidade e seguro contra-doença, acidente ou incapacidade, aposentadoria, acesso a qualquer função no serviço público sem distinção de estado civil, licença maternidade de três meses com direito ao salário integral, participação preferencialmente de mulheres na direção e administração de programas de assistência social (materno-infantil, trabalho feminino e organização do lar), exigência de apoio e proteção às mães e às crianças, em todos níveis de governo, através de garantias legais e instituição de serviços especializados. Ver Besse, 1991, p. 189.

\section{REFERÊNCIAS}

BADINTER, Elisabeth (Org.). Palavras de homens: 1790-1793. Rio de Janeiro, Nova Fronteira, 1991.

BESSE, Susan K. Modernizando a desigualdade. São Paulo, EDUSP, 1999.

CARDOSO, Elizangela Barbosa. Múltiplas e singulares: história e memória de estudantes universitárias. 2. ed. Teresina: EDUFPI, 2012. 
ASTELO BRANCO, Pedro Vilarinho. Mulheres plurais. Teresina: Fundação Cultural Monsenhor Chaves, 1996.

BOCK, Gisela. Pobreza feminina, maternidade e direitos das mães na ascensão dos Estados-providência (1890-1950). In: DUBY, Georges; PERROT, Michelle (Dir.). História das mulheres no Ocidente. Porto, Afrontamento, v. 5, 1995, p. 440-453.

GONÇALVES, Wilson Carvalho. Dicionário enciclopédico piauiense ilustrado: 1549-2003. Teresina: Halley, 2003.

HAHNER, June E. A mulher brasileira e suas lutas sociais e políticas: 18501937. São Paulo, Brasiliense, 1981.

KAPPELI, Anne-Marie. Cenas feministas. In: DUBY, Georges; PERROT, M. (Dir.). História das mulheres no Ocidente: o século XIX. Porto: Afrontamento, 1994. v. 4. p. 540-579.

QUEIROZ, Teresinha. Os literatos e a República: Clodoaldo Freitas, Higino Cunha e as tiranias do tempo. 2. ed. Teresina, EDUFPI, 1998.

MAGALHAES, Maria Socorro Rios. Literatura piauiense: horizontes de leitura e crítica literária. Teresina: Fundação Cultural Monsenhor Chaves, 1998.

PERROT, Michelle. Mulheres públicas. São Paulo: UNESP, 1998.

ROCHA, Olívia Candeia Lima. Lugares, saber e poder: apropriação feminina sobre as práticas discursivas entre 1875-1950. 2007. Dissertação de Mestrado em História do Brasil, Universidade Federal do Piauí, 2007.

SCOTT, Joan. A cidadã paradoxal: as feministas francesas e os direitos do homem. Florianópolis: Ed. Mulheres, 2002.

SOIHET, Rachel. Zombaria como arma antifeminista: instrumento conservador entre libertários. Estudos Feministas, Florianópolis, n. 13, v. 3, p. 591-611, 2005a.

SOIHET, Rachel.Feminismo X antifeminismo de libertários: a luta das mulheres pela cidadania durante o regime autoritário. In: SOIHET, Rachel; BICALHO, Maria Fernanda Baptista; GOUVEA, Maria de Fátima (Org.). Culturas políticas: ensaios de história cultural, história política e ensino de história. Rio de Janeiro: Mauad, 2005b. p. 307-332 
SOIHET, Rachel. Formas de violência, relações de gênero e feminismo. Gênero, Niterói, n. 2, p. 7-25, 2002.

SOIHET, Rachel. Violência simbólica: saberes masculinos e representações femininas. Estudos Feministas, Florianópolis, n. 5, v. 1, p. 7-29, 1997.

THÉBAUD, Françoise. A Grande Guerra: o triunfo da divisão sexual. In: DUBY, Georges; PERROT, Michelle (Dir.). História das mulheres no Ocidente. Porto: Afrontamento, v. 5, 1995. p.31-94.

THÉBAUD, Françoise. Introdução. In: DUBY, Georges; PERROT, Michelle (Dir.). História das mulheres no Ocidente: o século XX. Porto: Afrontamento, v. 5, 1995. p. 9-23. 